\title{
PAPER
}

\section{Numerical magnitude processing impairments in genetic syndromes: a cross-syndrome comparison of Turner and 22q11.2 deletion syndromes}

\section{Carmen Brankaer, ${ }^{1}$ Pol Ghesquière, ${ }_{1}^{1}$ Anke De Wel, ${ }^{2}$ Ann Swillen ${ }^{3}$ and Bert De Smedt ${ }^{1}$}

1. Parenting and Special Education Research Unit, Faculty of Psychology and Educational Sciences, University of Leuven, Belgium

2. Center for Developmental Disorders, University Hospital Gasthuisberg, University of Leuven, Belgium

3. Center for Human Genetics, Faculty of Medicine, University of Leuven, Belgium

\begin{abstract}
Cross-syndrome comparisons offer an important window onto understanding heterogeneity in mathematical learning disabilities or dyscalculia. The present study therefore investigated symbolic numerical magnitude processing in two genetic syndromes that are both characterized by mathematical learning disabilities: Turner syndrome and 22q11.2 deletion syndrome (22q11DS). We further verified whether the phenotypic outcomes of these syndromes emerged from the same or different cognitive processes and therefore examined whether numerical impairments were related to working memory deficits, often observed in these syndromes. Participants were 24 girls with Turner syndrome, 25 children with $22 q 11 D S$ and 48 well-matched typically developing control children. All children completed a symbolic numerical magnitude comparison task and four additional working memory tasks. Both groups of children with genetic syndromes showed similar impairments in symbolic numerical magnitude processing compared to typically developing controls. Importantly, in Turner syndrome, group differences in symbolic numerical magnitude processing disappeared when their difficulties in visual-spatial working memory were taken into account. In contrast, the difficulties in 22q11DS were not explained by poor visual-spatial working memory. These data suggest that different factors underlie the symbolic numerical magnitude processing impairments in both patient groups with mathematical learning disabilities and highlight the value of cross-syndrome comparisons for understanding different pathways to mathematical learning disabilities or dyscalculia.
\end{abstract}

\section{Research highlights}

- Cross-syndrome comparisons are a window onto understanding heterogeneity in mathematical learning disabilities (MLD) or dyscalculia.

- Children with Turner syndrome and 22q11 deletion syndrome show deficits in symbolic numerical magnitude processing.

- Visuospatial working memory difficulties explain numerical deficits in Turner but not in 22q11 deletion syndrome.

- MLD/ dyscalculia is associated with visual-spatial impairments in only a subgroup of children.

\section{Introduction}

Dyscalculia, or mathematical learning disabilities (MLD), occur frequently in genetic syndromes as a part of their behavioral phenotype (Ansari \& KarmiloffSmith, 2002). Numeracy deficits have been reported in a variety of syndromes, such as Turner syndrome (e.g. Bruandet, Molko, Cohen \& Dehaene, 2004), 22q11.2 deletion syndrome (22q11DS; e.g. De Smedt, Swillen, Verschaffel \& Ghesquière, 2009c), Williams syndrome (e.g. Libertus, Feigenson, Halberda \& Landau, 2014), Down syndrome (e.g. Sella, Lanfranchi \& Zorzi, 2013) and Fragile X syndrome (e.g. Murphy, Mazzocco, 
Gerner \& Henry, 2006). Given the heterogeneity in etiology and in the manifestation of mathematical learning disabilities or dyscalculia (Kaufmann, Mazzocco, Dowker, von Aster, Göbel et al., 2013; Rubinsten \& Henik, 2009), cross-syndrome comparisons are a window onto the characteristics of individuals with MLD in general. These cross-syndrome comparisons might help to get a better understanding of the heterogeneous relationship between MLD and its underlying cognitive and neurobiological mechanisms (Dennis, Berch \& Mazzocco, 2009). In this context, previous studies have pointed to the differential roles of language (Paterson, Girelli, Butterworth \& Karmiloff-Smith, 2006) and counting skills (Murphy et al., 2006) in the mathematical impairments that patients with genetic syndromes experience. Few studies, however, have investigated the roles of numerical magnitude processing in genetic disorders, although research has highlighted the importance of this ability for the development of mathematics achievement (e.g. Butterworth, Varma \& Laurillard, 2011; see De Smedt, Noël, Gilmore \& Ansari, 2013 for a narrative review and Schneider, Beeres, Coban, Merz, Schmidt et al., 2016, for a meta-analysis) and numerical magnitude processing impairments have been observed in several genetic syndromes (see Simon, 2011, for an overview). Against this background, the aim of the present study was to investigate numerical magnitude processing in two syndromes with different genetic etiologies. We focused on children with Turner syndrome and children with 22q11DS because numerical magnitude processing impairments have been reported in both patient groups (De Smedt et al., 2009c; Mazzocco, 2009), and because patients with normal intellectual abilities are found in both populations. This is in contrast to other genetic syndromes in which numerical deficits have been studied, such as Williams syndrome or Down syndrome (e.g. Van Herwegen \& Karmiloff-Smith, 2015), which are characterized by intellectual disabilities. In the remainder of this introduction, we first focus on numerical magnitude processing and its relationship with mathematics achievement. In addition, an overview of the numerical magnitude processing impairments in children with Turner syndrome and in 22q11DS is provided. Finally, the goal and the design of the present study are presented.

\section{Numerical magnitude processing}

Several studies have demonstrated that the ability to understand and process numerical magnitude information is related to (e.g. Holloway \& Ansari, 2009) and even predictive of (e.g. De Smedt, Verschaffel \& Ghesquière, 2009d; Halberda, Mazzocco \& Feigenson,
2008; Mazzocco, Feigenson \& Halberda, 2011) individual differences in mathematics achievement. Moreover, it has been widely documented that children with MLD experience particular difficulties in numerical magnitude processing (De Smedt et al., 2013; Noël \& Rousselle, 2011). A typical and well-established paradigm to examine numerical magnitude processing is the numerical magnitude comparison task (Sekuler \& Mierkiewicz, 1977) in which participants have to identify the numerically larger of two presented numerical magnitudes. These magnitudes can be presented in either a nonsymbolic (dot arrays) or symbolic (Arabic digits) format (De Smedt et al., 2013). Findings on the relationship between non-symbolic numerical magnitude comparison and mathematics achievement are mixed, as some studies found that an individual's ability to compare dot arrays was significantly associated with their performance on a mathematics achievement test (Halberda et al., 2008; Libertus, Feigenson \& Halberda, 2011; Mazzocco et al., 2011), while other studies did not (e.g. De Smedt \& Gilmore, 2011; Holloway \& Ansari, 2009; Vanbinst, Ghesquière \& De Smedt, 2012). Two recent metaanalyses have shown that the association between non-symbolic numerical magnitude processing and mathematics achievement, although significant, tends to be weak, especially beyond the age of 6 years $(r=.20$ in Chen \& Li, 2014; $r=.22$ in Fazio, Bailey, Thompson \& Siegler, 2014). On the other hand, the relationship between symbolic numerical magnitude comparison and mathematics achievement seems to be more consistent across studies (e.g. Bugden \& Ansari, 2011; De Smedt et al., 2009d; Kolkman, Kroesbergen \& Leseman, 2013; Vanbinst, Ceulemans, Ghesquière \& De Smedt, 2015) and it has been suggested that symbolic numerical magnitude processing, in particular, plays an important role in the development of mathematical abilities (De Smedt et al., 2013, for a narrative review). Recent metaanalytic data suggest that this indeed is the case (Schneider et al., 2016). More specifically, Schneider et al. (2016) showed that the effect size of the association between numerical magnitude processing and mathematics achievement was significantly higher for symbolic $(r=.30)$ than for non-symbolic $(r=.24)$ comparison. Against this background, the current study specifically focused on symbolic numerical magnitude processing.

\section{Numerical magnitude processing in Turner syndrome and 22q11DS}

Mathematical learning disabilities have been described as a part of the cognitive phenotype in both Turner and 22q11DS syndromes. Moreover, in both conditions, numerical magnitude processing deficits and spatial 
impairments as well as structural and functional posterior parietal lobe abnormalities that might contribute to these learning disabilities have been reported (see Mazzocco, 2009; De Smedt et al., 2009c, for reviews).

Turner syndrome is a genetic disorder that results from the complete or partial loss of one of the two $\mathrm{X}$ chromosomes. This syndrome affects approximately 1 out of every 2500 female live births and is associated with a number of characteristic physical features, such as a short stature, neck webbing, low-set ears and ovarian dysgenesis (see Davenport, Hooper \& Zeger, 2007, for an overview). Most patients with Turner syndrome have an intellectual ability within the normal range, although their IQ profile is often characterized by a Verbal IQ (VIQ)-Performance IQ (PIQ) discrepancy, in favor of the VIQ. The cognitive phenotype of females with Turner syndrome is characterized by relative strengths in the verbal domain and deficits in attentional, visual-spatial and executive functions, including working memory (Mazzocco, 2009; Rovet, 2004).

Several studies have demonstrated poor mathematics performance in patients with Turner syndrome (e.g. Bruandet et al., 2004; Murphy et al., 2006; Rovet, 1993; see Mazzocco, 2009, for a review). More specifically, it has been documented that these patients experience particular problems with numerical magnitude processing: Bruandet et al. (2004) studied the performance of 12 adults with Turner syndrome on a variety of cognitive tests and found that these participants were impaired in their subitizing (i.e. enumerating numerosities of 4 or less) and cognitive estimation skills (e.g. estimating the length of a bus), but not in counting (i.e. enumerating numerosities larger than 4). Simon, Takarae, De Boer, McDonald-McGinn, Zackai et al. (2008) examined numerical magnitude processing in school-aged girls with Turner syndrome and observed that these children were impaired on a symbolic and non-symbolic numerical magnitude comparison task. These authors also observed difficulties in subitizing and although there were no statistically significant differences in counting compared to controls, this small sample of children with Turner syndrome $(n=11)$ performed approximately $1 S D$ slower than controls, suggesting clear difficulties in their counting abilities. Relatedly, Mazzocco and Hanich (2010) demonstrated that girls with Turner syndrome experienced particular problems on a task with numerical processing demands, i.e. a symbolic numerical decomposition task in which participants quickly had to evaluate whether presented number pairs totaled a given target number. These numerical deficits in Turner syndrome have been related to structural and functional abnormalities in the posterior parietal cortex (Molko, Cachia, Rivière, Mangin, Bruandet et al., 2003,
2004), a brain region that is involved in the processing of numerical magnitudes (see Menon, 2015).

22q11DS is a genetic deletion syndrome that results from a submicroscopic deletion at band 11.2 on the long (q) arm of chromosome 22 and affects around 1 in 2000/4000 live births (McDonald-McGinn, Sullivan, Marino, Philip, Swillen et al., 2015). A wide phenotypic variability is observed, but major characteristics are velopharyngeal anomalies, congenital cardiac defects and mild facial dysmorphism (broad nasal bridge, small mouth and low-set ears). Most patients with 22q11DS have lower intellectual abilities, with about $55 \%$ of the patients scoring in the borderline to normal intellectual range (IQ > 70) and about 45\% having a (mild to moderate) intellectual disability; the IQ profile of these patients is often characterized (during primary school age) by better verbal than performance abilities (De Smedt, Devriendt, Fryns, Vogels, Gewillig et al., 2007a; De Smedt et al., 2009c). They also show remarkable difficulties in attention and visual-spatial working memory, despite preserved verbal memory skills (Bearden, Woodin, Wang, Moss, McDonald-McGinn et al., 2001; Simon, Bearden, McDonald-McGinn \& Zackai, 2005a).

Previous research has shown that patients with 22q11DS have normal scores for reading and spelling, but show substantial deficits in mathematics (e.g. De Smedt, Reynvoet, Swillen, Verschaffel, Boets et al., 2009b; De Smedt, Swillen, Devriendt, Fryns, Verschaffel et al., 2007b; Woodin, Wang, Aleman, McDonaldMcGinn, Zackai et al., 2001). Simon et al. (2005a) were among the first to investigate basic numerical skills in children with 22q11DS. They found that 7- to 14-yearolds with 22q11DS were impaired in counting, but not in subitizing (see also Simon et al., 2008). Children with 22q11DS also performed more poorly on both a symbolic and a non-symbolic numerical magnitude comparison task compared to matched controls. In accordance with these findings, De Smedt, Swillen, Devriendt, Fryns, Verschaffel et al. (2006) observed that 6- to 10year-olds with 22q11DS performed more slowly in counting, but not subitizing, and tended to be slower in numerical magnitude comparison than controls, although this latter group difference failed to reach statistical significance due to a small sample size. Other studies, however, found significant group differences in reaction time on symbolic (De Smedt et al., 2007b; De Smedt et al., 2009b; Simon et al., 2008) and nonsymbolic (Simon et al., 2008) numerical magnitude comparison tasks, indicating that patients with 22q11DS experience particular difficulties in comparing numerical magnitudes. These numerical difficulties have also been associated with structural and functional 
abnormalities within the posterior and fronto-parietal networks that subserve typical mathematical cognition (De Smedt et al., 2009c; Simon et al., 2005a; Simon, Bish, Bearden, Ding, Ferrante et al., 2005b).

To summarize, Turner syndrome and 22q11DS have different genetic etiologies, yet on a surface level they both show abnormalities in numerical magnitude processing, spatial abilities and the brain networks that support these skills. These similar phenotypic outcomes might, however, emerge from very different low-level cognitive processes (Van Herwegen \& Karmiloff-Smith, 2015). Therefore, a direct comparison between Turner syndrome and 22q11DS is needed to empirically test whether both syndrome populations show similar impairments in numerical processing and whether these impairments arise from the same or different cognitive factors.

To the best of our knowledge, only one crosssyndrome comparison on numerical magnitude processing in Turner and 22q11DS syndromes has been reported (Simon et al., 2008). These authors compared 7- to 14year-olds with Turner syndrome and 22q11DS and showed that the syndrome groups did not differ in enumeration and numerical magnitude comparison, although both groups performed more poorly than typically developing control children. Simon et al. (2008) therefore suggested that both syndromes share a common set of numerical impairments. Nevertheless, it is possible that similar impairments in numerical magnitude processing at the behavioral level originate from different underlying cognitive causes (Butterworth \& Kovas, 2013; Kaufmann et al., 2013; Rubinsten \& Henik, 2009), such as working memory or spatial abilities. This possibility cannot, however, be explored with the data of Simon et al. (2008) because no working memory measures or visual-spatial tasks were included in this study.

Both patients with Turner syndrome (Bray, Dunkin, Hong \& Reiss, 2011; Buchanan, Pavlovic \& Rovet, 1998) and 22q11DS (Bearden et al., 2001; Sobin, KileyBrabeck, Daniel, Khuri, Taylor et al., 2005; Woodin et al., 2001) experience problems with working memory, in particular its visual-spatial component. In view of the abundant literature on the association between MLD and working memory deficits (see Friso-van den Bos, van der Ven, Kroesbergen \& van Luit, 2013, for a metaanalysis) and the reported associations between various working memory components and symbolic and nonsymbolic numerical magnitude processing (Gullick, Sprute \& Temple, 2011; Passolunghi \& Lanfranchi, 2012; Xenidou-Dervou, De Smedt, van der Schoot \& van Lieshout, 2013), it is possible that these working memory deficits underlie the numerical magnitude processing impairments in children with Turner syndrome and/or in children with 22q11DS.

\section{The present study}

The main goal of the present study was to investigate symbolic numerical magnitude processing and its association with working memory in two genetic disorders that are known to be associated with MLD: Turner syndrome and 22q11DS. The performance of both patient groups was compared to the performance of a well-matched group of control children. It is important to point out that intellectual disabilities are often reported in children with 22q11DS, i.e. on average $45 \%$ of the children in this patient group have an IQ below 70 (De Smedt et al., 2007a). In order to make our 22q11DS group as comparable as possible to patients with Turner syndrome and in order to exclude intellectual disabilities in our sample, we only selected children with 22q11DS who had an IQ in the borderline to normal range (IQ > 70). As a result, our findings on 22q11DS mainly apply to this subgroup of children with 22q11DS.

Children's numerical magnitude processing skills were investigated by means of a symbolic numerical magnitude comparison task with Arabic digits. In view of the studies reviewed above, we predicted that both children with Turner syndrome and children with 22q11DS would perform more poorly than typically developing matched controls but that the two patient groups would not differ in their performance.

Extending the cross-syndrome comparison by Simon et al. (2008), we also investigated the impact of working memory on symbolic numerical magnitude processing. To this end, Baddeley's well-known multi-component model of working memory (Baddeley, 2003) was employed. This model includes two slave systems that are specialized for the temporary storage of phonological and visual-spatial information: the phonological loop and the visual-spatial sketchpad. A third component is the central executive, a system that controls and regulates the information stored within the slave systems. Based on prior research (e.g. Bearden et al., 2001; Bray et al., 2011; Buchanan et al., 1998; Sobin et al., 2005; Woodin et al., 2001), we hypothesized that both children with Turner syndrome and 22q11DS would be impaired in their working memory capacities, and especially on visual-spatial sketchpad measures. Given the positive association between working memory and symbolic numerical magnitude processing (Gullick et al., 2011; Passolunghi \& Lanfranchi, 2012; Xenidou-Dervou et al., 2013), significant associations between the working memory tasks and the symbolic numerical magnitude comparison task were also expected. 


\section{Method}

\section{Participants}

Participants were 98 children between the ages of 6 and 12 years: 24 girls with Turner syndrome, 25 children with 22q11DS (11 boys, 14 girls) and 49 control children (12 boys, 37 girls). For all participating children, written parental consent was obtained.

Children with Turner syndrome were recruited from a group of patients followed at the University Hospitals of Leuven, Ghent and Brussels (Belgium) and from contacts with a Turner patient association. This subsample comprised 15 girls with a 45,X karyotype, six girls with a mosaic expression and three girls with another $\mathrm{X}$-chromosomal abnormality (i.e. isochromosome or a partial deletion of the $\mathrm{X}$ chromosome). Nineteen girls received growth hormone. Children with brain damage or an intellectual disability (IQ $<70$ ) and bilingual children were excluded. In the context of a previous study (De Wel, De Smedt \& Swillen, 2009), a control group of 24 typically developing girls was selected who matched the sample of girls with Turner syndrome in terms of chronological age, intellectual ability, educational environment and socioeconomic background.

Children with 22q11DS were recruited from a group of patients followed at the Center for Human Genetics of the University Hospital of Leuven (Belgium). In all participants, diagnosis of 22q11DS was confirmed by means of fluorescence in situ hybridization (FISH) and all children had a de novo deletion. Children with an intellectual disability $(\mathrm{IQ}<70)$, children with severe physical disabilities or brain damage and bilingual children were excluded. In the light of a previous study (De Smedt et al., 2009b), an extensive preparatory study was conducted to find a control group of 25 children who individually matched these participants with 22q11DS as closely as possible in terms of sex, chronological age, intellectual ability, educational environment and socioeconomic background.

One child of the control group matched to the children with Turner syndrome was further excluded due to her extremely slow and outlying performance on the symbolic numerical magnitude comparison task ( $M=2321 \mathrm{~ms}$ ), which was $4.5 S D$ slower than the control group mean and $4.5 S D$ and $4 S D$ slower than the 22q11DS and Turner group means, respectively. As a result, the control group matched to the children with Turner syndrome only comprised 23 children. The control group matched to Turner syndrome $(n=23)$ did not differ from the control group matched to $22 q 11 \mathrm{DS}(n=25)$ in terms of chronological age,
Table 1 Descriptive statistics of the samples

\begin{tabular}{|c|c|c|c|c|c|c|}
\hline \multirow[b]{2}{*}{ Variable } & \multicolumn{2}{|c|}{$\begin{array}{l}\text { Turner } \\
\text { syndrome } \\
(n=24)\end{array}$} & \multicolumn{2}{|c|}{$\begin{array}{l}22 \mathrm{q} 11 \mathrm{DS} \\
(n=25)\end{array}$} & \multicolumn{2}{|c|}{$\begin{array}{l}\text { Controls } \\
(n=48)\end{array}$} \\
\hline & $M$ & $S D$ & $M$ & $S D$ & $M$ & $S D$ \\
\hline Non-verbal IQ ${ }^{\mathrm{a}}$ & 92.42 & 15.24 & 77.52 & 13.17 & 94.60 & 14.00 \\
\hline Verbal $\mathrm{IQ}^{\mathrm{b}}$ & 105.59 & 15.83 & 93.52 & 13.18 & 109.32 & 12.76 \\
\hline Processing speed ${ }^{\mathrm{c}}$ & 47.46 & 8.77 & 44.70 & 8.85 & 47.17 & 10.35 \\
\hline SES & 4.13 & 1.11 & 4.02 & 0.91 & 3.75 & 1.03 \\
\hline Age in years & 9.30 & 1.94 & 9.83 & 1.89 & 9.36 & 1.75 \\
\hline
\end{tabular}

Note: ${ }^{\text {a }} \mathrm{IQ}$ score on Raven's Standard Progressive Matrices. ${ }^{\mathrm{b}} \mathrm{IQ}$ score on the Verbal Analogies subtest. ${ }^{\mathrm{c}}$ Total time (s) to name the stimuli on the Object Naming task.

intellectual ability or socioeconomic background $(p s>.43)$. Because both groups of selected control children did not differ in these variables, all were included in one control group. None of these control children was bilingual or had a medical history, a developmental disorder or familial occurrence of developmental disorders. This final control group consisted of 48 children (12 boys, 36 girls).

Table 1 shows the descriptive statistics of the participants. There were no group differences in chronological age $\left(F(2,94)=0.67, p=.51, \eta_{p}^{2}=.01\right)$, socioeconomic background $\left(F(2,94)=1.27, p=.29, \eta_{p}^{2}=.03\right)$, or processing speed $\left(F(2,88)=0.65, p=.52, \eta_{p}^{2}=.01\right)$. The groups differed in non-verbal $(F(2,94)=12.66$, $\left.p<.01, \eta_{p}^{2}=.21\right)$ and verbal IQ $(F(2,91)=11.09$, $\left.p<.01, \eta_{p}^{2}=.20\right)$ : Children with Turner syndrome did not differ from controls $(p s>.54)$, but children with 22q11DS had significantly lower intellectual abilities than control children (non-verbal: $p<.01, d=-1.26$; verbal: $p<.01, d=-1.24)$ and children with Turner syndrome (non-verbal: $p<.01, d=-1.07$; verbal: $p<.01, d=-0.85)$. These group differences were considered in subsequent analyses.

\section{Measures}

Symbolic numerical magnitude comparison

A classic symbolic numerical magnitude comparison task was administered (Sekuler \& Mierkiewicz, 1977). In this task, children indicated the numerically larger of two simultaneously presented Arabic digits. Stimuli comprised all combinations of the numbers 1 to 9, yielding 72 trials. They were presented in white on a black background in Arial font (size 72) using the AFFECT 3.0 software (Hermans, Clarysse, Baeyens \& Spruyt, 2002) on a 17-inch laptop. A trial started with a $200 \mathrm{~ms}$ 
fixation cross in the center of the computer screen accompanied by a beep of $440 \mathrm{~Hz}$. After $1000 \mathrm{~ms}$, the stimulus appeared in the center of the screen and remained visible until the child responded. The position of the largest number was counterbalanced. Children were instructed to perform both accurately and quickly. Answers and reaction times were registered by the laptop. Each trial was initiated by the experimenter with a control key. Children were required to select the larger of two response alternatives, one displayed on the left and one displayed on the right, by pressing a key on the side of the larger one. Key presses were made on an external computer keyboard that was put in front of the laptop and was connected to it. The left response key, labeled with a blue sticker was 'd', the right response key, labeled with a yellow sticker was ' $\mathrm{k}$ '. Three practice trials were included to familiarize the child with the key assignments.

\section{Working memory}

Four different tasks were administered to assess children's working memory. These tasks were previously used in De Smedt, Janssen, Bouwens, Verschaffel, Boets et al. (2009a) on the association between working memory and mathematics achievement in first and second graders. All tasks followed the same span procedure: Three trials for each span length were presented and the span length increased when children recalled at least two out of three trials of the same span length correctly. When children failed to do this, testing was terminated. Each task was preceded by two practice trials to familiarize children with the task.

Phonological loop. The Digit Span Forward task involved the immediate recall of increasingly longer series of digits between 1 and 9. For each span length, the stimuli of the first two trials were taken from the Wechsler Intelligence Scale for Children - 3rd Edition (WISC-III; Wechsler, 1992) and the third trial was selected from the WMTB-C (Pickering \& Gathercole, 2001). All series of digits were presented acoustically and were recorded to standardize the assessment.

Visual-spatial sketchpad. In the Corsi Block task, taken from the Working Memory Test Battery for Children (WMTB-C; Pickering \& Gathercole, 2001), the experimenter tapped out a sequence of blocks, at a rate of one block per second, on a board with nine identical blocks. Children were instructed to exactly reproduce the sequence. All sequences were random and no block was tapped more than once within a sequence.
Central executive. The construction and administration of the Digit Span Backward task was similar to the Digit Span Forward task, except that children had to recall the sequence of acoustically presented digits in the reverse order.

We also used a Listening Span task (Pickering \& Gathercole, 2001), translated in to Dutch, to assess the central executive component. In this task, children were asked to judge the correctness of a series of recorded sentences (correct vs. false). They were further instructed to memorize the last word in every sentence, and to recall those words in the correct order at the end of each trial. All the sentences used in the listening span task were of equal length and were obviously correct or false. They all ended on high-frequency words.

\section{Additional measures}

Intellectual ability. Non-verbal intellectual ability: Raven's Standard Progressive Matrices (Raven, Court \& Raven, 1992) was used as a measure of non-verbal intellectual ability. For each child, a standardized score $(M=100 ; S D=15)$ was calculated.

Verbal intellectual ability: The Verbal Analogies subtest of the Revisie Amsterdamse Kinder Intelligentie Test (RAKIT; Bleichrodt, Drenth, Zaal \& Resing, 1987), which is a standardized Dutch intelligence test for children, was used as a measure of verbal intellectual ability. In this subtest, 30 items of the form ' $\mathrm{A}$ is to B as $\mathrm{C}$ is to ...' were presented and children were asked to select the appropriate answer from four response options. For each child, a standardized score $(M=100 ; S D=15)$ was calculated.

Socioeconomic status. To obtain a marker of socioeconomic status, all parents were asked to report their educational level and all were accordingly classified into the standardized categories of the International Standard of Classification of Education system, developed by the UNESCO (OECD, 1999).

Processing speed. To exclude the possibility that reaction time differences on the symbolic numerical magnitude comparison task would be explained by differences in processing speed, we included a classic Rapid Automatized Naming (RAN) task (Denckla \& Rudel, 1976) as a control measure. We administered the objects naming task in which a card with 50 stimuli was presented, which participants had to name as fast as possible, without making any errors. Stimuli were five high-frequency objects (tree, duck, chair, scissors and bicycle) that were repeated in a random order, with each 
stimulus appearing 10 times. The score on this task consisted of the time needed to name all stimuli.

\section{Statistical analyses}

One-way ANOVAs were used to evaluate group differences. Post-hoc $t$-tests were Tukey corrected. Partial-eta squared and Cohen's $d$ were computed as measures of effect size.

\section{Results}

\section{Symbolic numerical magnitude comparison}

Children's performance on the symbolic numerical magnitude comparison task is shown in Table 2. Accuracy on this task was very high and at ceiling in all three groups. Only a trend towards a group difference was observed, $\left.F(2,94)=2.56, p=.08, \eta_{p}{ }^{2}=.05\right)$. Post-hoc comparisons showed that control children performed as accurately as children with Turner syndrome $(p=.80)$ and children with 22q11DS $(p=.17)$. Children with Turner syndrome tended to perform less accurately than children with 22q11DS, but this difference was not significant $(p=.09)$.

Reaction times were based on correct responses only. There were group differences in reaction time $(F(2$, $\left.94)=7.53, p<.01, \eta_{p}{ }^{2}=.14\right)$, demonstrating that children with Turner syndrome $(p<.01, d=0.82)$ and 22q11DS $(p<.01, d=0.85)$ were significantly slower than controls; there were no group differences between children with Turner syndrome and children with 22q11DS $(p>.99)$. Group differences remained when intellectual ability was additionally controlled for (nonverbal: $F(2,93)=6.19, p<.01, \eta_{p}{ }^{2}=.12$; verbal: $F(2$, $90)=6.10, p<.01, \eta_{p}{ }^{2}=.12$ ). Post-hoc $t$-tests indicated that children with Turner syndrome remained significantly slower than controls (non-verbal $p<.01, d=0.80$; verbal $p<.01, d=.87$ ) and that there were again no

Table 2 Children's performance on the symbolic magnitude comparison task

\begin{tabular}{|c|c|c|c|c|c|c|}
\hline \multirow[b]{2}{*}{ Variable } & \multicolumn{2}{|c|}{$\begin{array}{l}\text { Turner } \\
\text { syndrome }\end{array}$} & \multicolumn{2}{|c|}{$22 q 11 D S$} & \multicolumn{2}{|c|}{ Controls } \\
\hline & $M$ & $S D$ & $M$ & $S D$ & $M$ & $S D$ \\
\hline $\begin{array}{l}\text { Accuracy } \\
\text { (\% correct) }\end{array}$ & 96 & 3 & 98 & 2 & 96 & 3 \\
\hline $\begin{array}{l}\text { Reaction time } \\
(\mathrm{ms})\end{array}$ & 1066.61 & 316.97 & 1061.85 & 277.11 & 852.77 & 235.88 \\
\hline Slope (ms) & -55.54 & 30.90 & -48.62 & 39.49 & -33.11 & 22.42 \\
\hline
\end{tabular}

group differences between children with Turner syndrome and children with 22q11DS ( $p s>.53$ ). The group difference between children with 22q11DS and controls, however, was considerably smaller after controlling for non-verbal ( $p=.03, d=.77)$ and disappeared after controlling for verbal $(p=.12)$ intellectual ability. All analyses on the reaction times were repeated with the processing speed measure as an additional covariate. The observed pattern of findings remained the same when processing speed was additionally controlled for.

To obtain more detailed information about children's performance on the symbolic numerical magnitude comparison task, we additionally calculated for each child the slope of the linear regression in which reaction time was predicted by numerical distance. This slope can be considered as an index of the numerical distance effect, with steeper slopes indicating larger distance effects (e.g. De Smedt et al., 2009d). As shown in Table 2, the mean slopes in all three groups were negative and significantly different from $0(t \mathrm{~s}<-6.16$, $p s<.01$ ), which reflects the negative relationship between numerical distance and children's reaction time. There were also significant group differences in children's slope on the numerical magnitude comparison task $\left(F(2,94)=5.24, p<.01, \eta_{p}{ }^{2}=.10\right)$, indicating that children with Turner syndrome had significantly steeper slopes than controls $(p<.01, d=-0.89)$, whereas there were no group differences between children with Turner syndrome and children with 22q11DS on the one hand $(p=.69)$ and only a trend towards a difference between children with 22q11DS and controls $(p=.09)$. A similar pattern of results emerged when intellectual ability was additionally controlled for (non-verbal: $F(2,93)=4.42$, $p=.01, \eta_{p}^{2}=.09$; verbal: $F(2,90)=4.62, p=.01$, $\left.\eta_{p}{ }^{2}=.09\right)$, demonstrating that the slopes of children with Turner syndrome remained significantly steeper than those of control children ( $p \mathrm{~s}=.01, d \mathrm{~s}>0.87)$, while no other group differences were found $(p s>.37)$. Again, these findings remained the same when processing speed was additionally controlled for.

\section{Working memory}

Children's performance on the working memory tasks is shown in Table 3 . There were significant group differences on the Digit Span Forward task $(F(2,88)=3.36$, $\left.p=.04, \eta_{p}{ }^{2}=.07\right)$ : Children with 22q11DS performed significantly better on this task than children with Turner syndrome $(p=.03, d=0.83)$, while no other significant group differences were found $(p s>.15)$. These group differences remained after controlling for intellectual ability (non-verbal: $F(2,87)=3.67, p=.03, \eta_{p}^{2}=.08$; verbal: $\left.F(2,84)=8.09, p<.01, \eta_{p}{ }^{2}=.12\right)$. 
Table 3 Children's performance (= number of correctly recalled items) on the administered working memory tasks

\begin{tabular}{|c|c|c|c|c|c|c|}
\hline \multirow[b]{2}{*}{ Variable } & \multicolumn{2}{|c|}{$\begin{array}{l}\text { Turner } \\
\text { syndrome }\end{array}$} & \multicolumn{2}{|c|}{$22 q 11 D S$} & \multicolumn{2}{|c|}{ Controls } \\
\hline & $M$ & $S D$ & $M$ & $S D$ & $M$ & $S D$ \\
\hline \multicolumn{7}{|l|}{ Phonological loop } \\
\hline Digit Span Forward & 8.76 & 1.73 & 10.32 & 2.06 & 9.77 & 2.18 \\
\hline Visual-spatial sketchpad & & & & & & \\
\hline Corsi Block & 7.52 & 1.78 & 8.88 & 2.37 & 9.97 & 2.08 \\
\hline \multicolumn{7}{|l|}{ Central executive } \\
\hline Digit Span Backward & 5.24 & 2.00 & 5.96 & 2.26 & 6.36 & 1.79 \\
\hline Listening Span & 6.43 & 1.75 & 5.56 & 1.66 & 6.07 & 2.16 \\
\hline
\end{tabular}

There were also significant group differences on the Corsi Block task $\left(F(2,88)=9.96, p<.01, \eta_{p}{ }^{2}=.18\right)$, showing that control children performed significantly better than children with Turner syndrome $(p<.01$, $d=1.33$ ). No differences between children with 22q11DS and control children $(p=.10)$ or between children with 22q11DS and children with Turner syndrome ( $p=.08)$ were observed. Group differences on the Corsi Block task remained when intellectual ability was additionally controlled for (non-verbal: $F(2,87)=9.40$, $p<.01, \eta_{p}{ }^{2}=.08$; verbal: $F(2,84)=9.32, p<.01$, $\left.\eta_{p}{ }^{2}=.16\right)$, indicating that children with Turner syndrome continued to have visual-spatial working memory problems compared to typically developing control children $(p \mathrm{~s}<.01, d \mathrm{~s}>-1.30)$.

No significant group differences on the Digit Span Backward $\left(F(2,88)=1.11, p=.33, \eta_{p}{ }^{2}=.02\right)$ and Listening Span task $\left(F(2,88)=2.01, p=.14, \eta_{p}{ }^{2}=.04\right)$ were found.

\section{Symbolic numerical magnitude comparison and working memory}

The above-mentioned analyses revealed that children with Turner syndrome experienced visual-spatial working memory problems compared to typically developing control children. To verify whether the above-reported group differences on the symbolic numerical magnitude comparison task could be explained by these problems in working memory, we reran the ANOVAs for symbolic numerical magnitude comparison with the Corsi Block task as an additional covariate.

With regard to reaction time, findings revealed that the group differences in numerical magnitude comparison remained when controlling for the Corsi Block task $\left(F(2,87)=3.11, p=.05, \eta_{p}^{2}=.07\right)$. Post-hoc comparisons indicated that children with Turner syndrome did not differ from control children $(p=.82)$, whereas children with 22q11DS continued to perform more
Table 4 Pearson partial correlation coefficients between the symbolic magnitude comparison task (reaction time and slope) and the Corsi Block task

\begin{tabular}{lllc}
\hline & \multicolumn{2}{l}{ Corsi Block task } & \\
\cline { 2 - 4 } & Turner syndrome & 22q11DS & Controls \\
\hline Reaction time (ms) & $-.60^{* *}$ & -.28 & $-.33^{*}$ \\
Slope (ms) & $.54^{*}$ & -.07 & .25 \\
\hline
\end{tabular}

Note: ${ }^{*} p<.05 ;{ }^{* *} p<.01$. Correlation coefficients were controlled for children's chronological age.

poorly than control children $(p=.04, d=0.57)$. Children with Turner syndrome and children with 22q11DS did not differ from each other $(p=.30)$.

Turning to the slopes on the symbolic numerical magnitude comparison task, the group differences between children with Turner syndrome and controls disappeared when the Corsi Block task was additionally controlled for $\left(F(2,87)=1.50, p=.23, \eta_{p}{ }^{2}=.03\right)$.

To better understand the associations between visualspatial working memory and symbolic numerical magnitude processing in the different participant groups, Pearson partial correlation coefficients between the Corsi Block task and the symbolic numerical magnitude comparison task were also calculated. Children's chronological age was included as a covariate in all analyses. As shown in Table 4, no significant correlations between the Corsi Block task and the symbolic magnitude comparison task were observed in children with 22q11DS; in control children there was a significant association between Corsi Block and children's reaction times but not the slope on the comparison task. In children with Turner syndrome, however, there were strong significant associations between this working memory task and children's reaction times and slopes on the comparison task, indicating that children with better visual-spatial working memory skills also performed faster and showed smaller distance effects on the symbolic numerical magnitude comparison task. The same pattern of findings was observed when processing speed was included as a partial variable in the analyses.

\section{Discussion}

In light of the heterogeneity in etiology and manifestation of mathematical learning disabilities or dyscalculia (Butterworth \& Kovas, 2013; Kaufmann et al., 2013; Rubinsten \& Henik, 2009), cross-syndrome comparisons of genetic syndromes in which MLD frequently occur as part of their cognitive phenotype might help to improve 
our understanding of the cognitive and neurobiological processes and heterogeneity that underlie MLD in general (Ansari \& Karmiloff-Smith, 2002). In view of behavioral data that have pointed to the importance of symbolic numerical magnitude processing for subsequent mathematical development (see De Smedt et al., 2013; Schneider et al., 2016), we investigated this domainspecific factor in two genetic syndromes that are associated with MLD, i.e. Turner syndrome and 22q11DS. These two syndromes were of particular interest because previous studies have indicated that both conditions are associated with MLD and numerical deficits (e.g. De Smedt et al., 2009b; De Smedt et al., 2007b; Mazzocco \& Hanich, 2010; Simon et al., 2008), spatial impairments (De Smedt et al., 2009c; Mazzocco, 2009), as well as with abnormalities in the posterior parietal cortex (Molko et al., 2003, 2004; Simon et al., 2005a; Simon et al., 2005b). The current data indicate that children with Turner syndrome and 22q11DS experience similar problems with the processing of symbolic magnitudes at the behavioral level. However, different cognitive factors seem to underlie these symbolic numerical magnitude processing problems in both groups: Symbolic difficulties were explained by impairments in visual-spatial memory in Turner syndrome, but not in 22q11DS. On the other hand, lowered intellectual ability instead of visual-spatial memory explained the difficulties in symbolic numerical magnitude processing in 22q11DS.

In line with previous studies, the present findings clearly demonstrate that children with Turner syndrome (Mazzocco \& Hanich, 2010; Simon et al., 2008) and 22q11DS (De Smedt et al., 2007b; De Smedt et al., 2009b; Simon et al., 2005a; Simon et al., 2008) experience particular problems with symbolic numerical magnitude comparison compared to typically developing control children, with the same pattern of findings being observed for the processing of small (1-4) as well as large (5-9) numerosities. In accordance with prior research in children with MLD (De Smedt et al., 2013), these problems were most pronounced when looking at the reaction time data, rather than at accuracy, and they were not explained by general processing speed. Further, we replicated the findings of Simon et al. (2008), who demonstrated that the syndrome groups did not differ in their symbolic numerical magnitude comparison skills at the behavioral level.

Does this imply that the symbolic numerical magnitude comparison difficulties in both populations result from the same cognitive deficits? To answer this question, we further investigated the role of working memory in children's symbolic numerical magnitude processing abilities. This was carried out because research in typically developing children revealed that symbolic numerical magnitude processing is associated with working memory (Gullick et al., 2011; Passolunghi \& Lanfranchi, 2012; Xenidou-Dervou et al., 2013) and because working memory impairments have been described in both Turner syndrome (Bray et al., 2011; Buchanan et al., 1998) and 22q11DS (Bearden et al., 2001; Sobin et al., 2005; Woodin et al., 2001). Against this background, we examined the three components of Baddeley's working memory model and examined their associations with symbolic numerical magnitude processing in our participant samples.

Consistent with the literature (Bray et al., 2011; Buchanan et al., 1998), girls with Turner syndrome performed more poorly than control children on the visual-spatial sketchpad measure. When controlling for this deficit in visual-spatial working memory, the group difference in symbolic numerical magnitude comparison between children with Turner syndrome and control children disappeared. This suggests that visual-spatial working memory plays an important role in the symbolic numerical magnitude processing impairments of children with Turner syndrome. This was also supported by the observation that in children with Turner syndrome, performance on the Corsi Block task was significantly and strongly associated with performance on the symbolic numerical magnitude comparison task, while this was not the case in the other two participant groups. The association between visual-spatial working memory difficulties and numeracy deficits in Turner syndrome might be explained by a disturbed development of the mental number line, which can be considered as the mental equivalent of a ruler (Bachot, Gevers, Fias \& Roeyers, 2005; Xenidou-Dervou, van der Schoot \& van Lieshout, 2015): The symbolic numerical magnitude comparison task requires participants to mentally represent numbers on a mental number line, with small numbers located to the left of larger ones (e.g. 9 follows 8 and is therefore larger than 8) and individuals with poorer visual-spatial skills might be impaired in the development of this mental number line (Van Herwegen \& Karmiloff-Smith, 2015).

Alternatively, the association between visual-spatial working memory and symbolic numerical magnitude processing could also be mediated by children's nonsymbolic magnitude representations. Indeed, children with poorer visual-spatial abilities might experience problems with non-symbolic magnitude processing (Rasmussen \& Bisanz, 2005), which in its turn might impede the development of symbolic numerical magnitude representations. Indeed, studies in typically developing children have suggested that symbolic digits become mapped onto a pre-existing system of approximate non- 
symbolic magnitude representations (e.g. Griffin, 2003; Mundy \& Gilmore, 2009), although recent data have challenged this idea that symbolic representations are grounded in these approximate non-symbolic representations of number (see Ansari, 2016, for a discussion). The present study did not, however, include such measures of approximate non-symbolic numerical magnitude processing and future studies should consider such measures in order to investigate this possibility. These studies should also verify whether the current findings remain when larger numerosities need to be processed, as the present study is limited to the investigation of only numbers $1-9$. On a related note, it needs to be emphasized that future studies should also consider how other aspects of numerical understanding, such as the understanding of cardinality (Chu, vanMarle \& Geary, 2013, 2015), ordinality (e.g. Goffin \& Ansari, 2016), or the spontaneous focus on numerosity (Hannula, Lepola \& Lehtinen, 2010) contribute to numerical development in Turner and 22q11DS syndromes.

With respect to the other working memory tasks, no deficits in central executive functioning in children with Turner syndrome were observed. This finding contrasts with prior research that reported executive dysfunction in these patients (e.g. Mazzocco \& Hanich, 2010; Ross, Stefanatos, Kushner, Zinn, Bondy et al., 2002). This inconsistency may be due to the executive measures that were used in the present study. Indeed, the central executive can be subdivided into different processes, such as shifting, updating and inhibition (Bull \& Scerif, 2001; Miyake, Friedman, Emerson, Witzki, Howerter et al., 2000). As demonstrated by St Clair-Thompson and Gathercole (2006), the Digit Span Backward and Listening Span tasks involve updating rather than other executive processes. Therefore, it is possible that patients with Turner syndrome are more impaired on central executive tasks that require executive functions other than updating. Furthermore, the central executive measures included in the present study mainly involved stimuli that were verbal in nature and it might be that, in view of the relatively superior verbal compared to visual abilities in these patients (Mazzocco, 2009), central executive impairments only become apparent if visual rather than verbal stimuli are used.

Contrary to our expectations (Bearden et al., 2001; Sobin et al., 2005; Woodin et al., 2001), children with 22q11DS performed at the same level as typically developing control children on the visual-spatial sketchpad measure. Therefore, visual-spatial working memory deficits cannot explain the poor symbolic numerical magnitude comparison performance of children with 22q11DS, suggesting a different developmental trajectory to the symbolic numerical magnitude processing difficulties in this syndrome. The fact that no visual-spatial deficits were observed in the 22q11DS participants is in line with De Smedt, Swillen, Devriendt, Fryns, Verschaffel et al. (2008), who found that visual-spatial working memory impairments in 22q11DS disappeared when differences in IQ were taken into account, indicating that poor visualspatial working memory in patients with 22q11DS might be related to their lowered intelligence. In this context, it is important to point out that we only included 22q11DS children with an IQ above 70, which was not always the case in previous studies on working memory and 22q11DS. This might explain the absence of group differences on the visual-spatial sketchpad measure, as the current data might represent a slight overestimation of the abilities of children with 22q11DS due to its restriction to the higher IQs.

Nevertheless, our participants with 22q11DS still had a lower intellectual ability than control children, and the group difference between these two groups on the symbolic numerical magnitude comparison task disappeared after controlling for this factor. This finding suggests that the problems that children with 22q11DS experience with symbolic numerical magnitude processing relate to their lowered intellectual ability, instead of to visual-spatial working memory as in Turner syndrome.

Although executive function deficits have been reported in 22q11DS (Sobin et al., 2005; Woodin et al., 2001), no group differences on the Digit Span Backward and Listening Span tasks were observed in the present study. Because both executive working memory tasks were verbal in nature, it is possible that our participants with 22q11DS compensated with their good phonological abilities (Bearden et al., 2001; De Smedt et al., 2009c; Sobin et al., 2005; Woodin et al., 2001). This possibility is strengthened by the observation that children with 22q11DS scored better on the phonological loop measure than children with Turner syndrome and a closer look at the data indicated that this group difference is mainly due to the excellent performance of the patients with 22q11DS.

As stated above, the present study only included 22q11DS children with an IQ score above 70, although $45 \%$ of this syndrome population has an intellectual disability (De Smedt et al., 2009c). Therefore, the present findings only relate to this subgroup and cannot be generalized to the entire population of 22q11DS. For example, it could be that children with 22q11DS with an IQ score below 70 show more prominent visuo-spatial working memory deficits, which in turn could explain their poor symbolic numerical magnitude processing skills. Relatedly, girls with different karyotypes were included in the Turner group. This within-group heterogeneity might have influenced the outcomes of the 
current study (see Rovet, 2004). Future research on the cognitive phenotypes of both syndrome groups should take these issues into account.

The current findings indicate that different cognitive factors (working memory vs. IQ) underlie the symbolic numerical magnitude processing problems in children with Turner syndrome and children with 22q11DS. Data from our participants with Turner syndrome further support the idea of a visual-spatial mediated pathway to MLD, as suggested by Geary (2004). However, in accordance with Bartelet, Ansari, Vaessen and Blomert (2014), data from the 22q11DS patients indicate that these visual-spatial impairments are only associated with MLD in a subgroup of children (see also Kaufmann et al. 2013, for a discussion on heterogeneity in MLD). This might explain why some studies did (e.g. Szücs, Devine, Soltesz, Nobes \& Gabriel, 2013) and other studies (e.g. Geary, Hamson \& Hoard, 2000) did not observe associations between MLD and visualspatial working memory. In sum, the present results highlight that, as suggested by Kaufmann et al. (2013), different pathways to behaviorally similar numerical processing deficits exist and provide additional evidence for the heterogeneity in cognitive mechanisms that underlie MLD or dyscalculia. These findings are not only crucial for the development of theoretical models of MLD, but also have important educational implications to set goals for remediation (Van Herwegen \& Karmiloff-Smith, 2015).

\section{Acknowledgements}

We would like to thank all children, families and schools who participated in the study. This study was partially supported by the Marguerite-Marie Delacroix Support Fund, by grant G.0946.12 of the Research Foundation Flanders (FWO), Belgium and by grant GOA 2012/010 of the KU Leuven Research Fund.

\section{References}

Ansari, D. (2016). Number symbols in the brain. In D. Berch, D. Geary, \& K. Mann-Koepke (Eds.), Development of mathematical cognition: Neural substrates and genetic influences (pp. 27-50). London: Elsevier.

Ansari, D., \& Karmiloff-Smith, A. (2002). Atypical trajectories of number development: a neuroconstructivist perspective. Trends in Cognitive Sciences, 6, 511-516.

Bachot, J., Gevers, W., Fias, W., \& Roeyers, H. (2005). Number sense in children with visuospatial disabilities: orientation of the mental number line. Psychology Science, 47, 172-183.
Baddeley, A. (2003). Working memory: looking back and looking forward. Nature Reviews Neuroscience, 4, 829-839.

Bartelet, D., Ansari, D., Vaessen, A., \& Blomert, L. (2014). Cognitive subtypes of mathematics learning disabilities in primary education. Research in Developmental Disabilities, 35, 657-670.

Bearden, C.E., Woodin, M.F., Wang, P.P., Moss, E., McDonald-McGinn, D. et al. (2001). The neurocognitive phenotype of the 22q11.2 deletion syndrome: selective deficit in visualspatial memory. Journal of Clinical and Experimental Neuropsychology, 23, 447-464.

Bleichrodt, N., Drenth, P.J.D., Zaal, J.N., \& Resing, W.C.M. (1987). RAKIT Handleiding bij de Revisie Amsterdamse Kinder Intelligentie Test. Lisse: Swets \& Zeitlinger.

Bray, S., Dunkin, B., Hong, D.S., \& Reiss, A.L. (2011). Reduced functional connectivity during working memory in Turner syndrome. Cerebral Cortex, 21, 2471-2481.

Bruandet, M., Molko, N., Cohen, L., \& Dehaene, S. (2004). A cognitive characterization of dyscalculia in Turner syndrome. Neuropsychologia, 42, 288-298.

Buchanan, L., Pavlovic, J., \& Rovet, J. (1998). A reexamination of the visuospatial deficit in Turner syndrome: contributions of working memory. Developmental Neuropsychology, 14, 341-367.

Bugden, S., \& Ansari, D. (2011). Individual differences in children's mathematical competence are related to the intentional but not automatic processing of Arabic numerals. Cognition, 118, 32-44.

Bull, R., \& Scerif, G. (2001). Executive functioning as a predictor of children's mathematics ability: inhibition, switching, and working memory. Developmental Neuropsychology, 19, 273-293.

Butterworth, B., \& Kovas, Y. (2013). Understanding neurocognitive developmental disorders can improve education for all. Science, 340, 300-305.

Butterworth, B., Varma, S., \& Laurillard, D. (2011). Dyscalculia: from brain to education. Science, 332, 1049-1053.

Chen, Q., \& Li, J. (2014). Association between individual differences in non-symbolic number acuity and math performance: a meta-analysis. Acta Psychologica, 148, 163-172.

Chu, F.W., vanMarle, K., \& Geary, D.C. (2013). Quantitative deficits of preschool children at risk for mathematical learning disability. Frontiers in Psychology, 4, 195.

Chu, F.W., vanMarle, K., \& Geary, D.C. (2015). Early numerical foundations of young children's mathematical development. Journal of Experimental Child Psychology, 132, 205-212.

Davenport, M.L., Hooper, S.R., \& Zeger, M. (2007). Turner syndrome in childhood. In M.M.M. Mazzocco, \& J.L. Ross (Eds.), Neurogenetic developmental disorders: Variation of manifestation in childhood (pp. 3-45). Cambridge, MA: MIT Press.

Denckla, M.B., \& Rudel, R.G. (1976). Rapid automatized naming (RAN): dyslexia differentiated from other learning disabilities. Neuropsychologia, 14, 471-479.

Dennis, M., Berch, D.B., \& Mazzocco, M.M.M. (2009). Mathematical learning disabilities in special populations: 
phenotypic variation and cross-disorder comparisons. Developmental Disabilities Research Reviews, 15, 80-89.

De Smedt, B., Devriendt, K., Fryns, J.P., Vogels, A., Gewillig, M. et al. (2007a). Intellectual abilities in a large sample of children with Velo-Cardio-Facial Syndrome: an update. Journal of Intellectual Disability Research, 51, 666-670.

De Smedt, B., \& Gilmore, C.K. (2011). Defective number module or impaired access? Numerical magnitude processing in first graders with mathematical difficulties. Journal of Experimental Child Psychology, 108, 278-292.

De Smedt, B., Janssen, R., Bouwens, K., Verschaffel, L., Boets, B. et al. (2009a). Working memory and individual differences in mathematics achievement: a longitudinal study from first grade to second grade. Journal of Experimental Child Psychology, 103, 186-201.

De Smedt, B., Noël, M.P., Gilmore, C., \& Ansari, D. (2013). The relationship between symbolic and non-symbolic numerical magnitude processing and the typical and atypical development of mathematics: evidence from brain and behavior. Trends in Neuroscience and Education, 2, 48-55.

De Smedt, B., Reynvoet, B., Swillen, A., Verschaffel, L., Boets, B. et al. (2009b). Basic number processing and difficulties in single-digit arithmetic: evidence from velo-cardio-facial syndrome. Cortex, 45, 177-188.

De Smedt, B., Swillen, A., Devriendt, K., Fryns, J.P., Verschaffel, L. et al. (2006). Mathematical disabilities in young primary school children with velo-cardio-facial syndrome. Genetic Counseling, 17, 259-280.

De Smedt, B., Swillen, A., Devriendt, K., Fryns, J.P., Verschaffel, L. et al. (2007b). Mathematical disabilities in children with velo-cardio-facial syndrome. Neuropsychologica, 45, 885-895.

De Smedt, B., Swillen, A., Devriendt, K., Fryns, J., Verschaffel, L. et al. (2008). Cognitive correlates of mathematical disabilities in children with velo-cardio-facial syndrome. Genetic Counseling, 19 (1), 71-94.

De Smedt, B., Swillen, A., Verschaffel, L., \& Ghesquière, P. (2009c). Mathematical learning disabilities in children with 22q11.2 deletion syndrome: a review. Developmental Disabilities Research Reviews, 15, 4-10.

De Smedt, B., Verschaffel, L., \& Ghesquiére, P. (2009d). The predictive value of numerical magnitude comparison for individual differences in mathematics achievement. Journal of Experimental Child Psychology, 103, 469-479.

De Wel, A., De Smedt, B., \& Swillen, A. (2009). Een cognitieve karakterisering van rekenstoornissen bij personen met het syndroom van Turner. TOKK: Tijdschrift voor Orthopedagogiek. Kinderpsychiatrie en Klinische Kinderpsychologie, 34, 102-118.

Fazio, L.K., Bailey, D.H., Thompson, C.A., \& Siegler, R.S. (2014). Relations of different types of numerical magnitude representations to each other and to mathematics achievement. Journal of Experimental Child Psychology, 123, 53-72.

Friso-van den Bos, I., van der Ven, S.H.G., Kroesbergen, E.H., \& van Luit, J.E.H. (2013). Working memory and mathematics in primary school children: a meta-analysis. Educational Research Review, 10, 29-44.
Geary, D.C. (2004). Mathematics and learning disabilities. Journal of Learning Disabilities, 37, 4-15.

Geary, D.C., Hamson, C.O., \& Hoard, M.K. (2000). Numerical and arithmetical cognition: a longitudinal study of process and concept deficits in children with learning disability. Journal of Experimental Child Psychology, 77, 236-263.

Goffin, C., \& Ansari, A. (2016). Beyond magnitude: judging ordinality of symbolic number is unrelated to magnitude comparison and independently relates to individual differences in arithmetic. Cognition, 150, 68-76.

Griffin, S. (2003). The development of math competence in the preschool and early school years: cognitive foundations and instructional strategies. In J.M. Royer (Ed.), Mathematical cognition (pp. 1-32). Greenwich, CT: Information Age Publishing.

Gullick, M.M., Sprute, L.A., \& Temple, E. (2011). Individual differences in working memory, nonverbal IQ, and mathematics achievement and brain mechanisms associated with symbolic and nonsymbolic number processing. Learning and Individual Differences, 21, 644-654.

Halberda, J., Mazzocco, M.M.M., \& Feigenson, L. (2008). Individual differences in non-verbal number acuity correlate with maths achievement. Nature, 455, 665-668.

Hannula, M.H., Lepola, J., \& Lehtinen, E. (2010). Spontaneous focusing on numerosity as a domain-specific predictor of arithmetical skills. Journal of Experimental Child Psychology, 107, 394-406.

Hermans, D., Clarysse, J., Baeyens, F., \& Spruyt, A. (2002). AFFECT (Version 3.0) [Computer software retrieved from http://www.psy.kuleuven.ac.be/leerpsy/affect]. University of Leuven, Belgium.

Holloway, I.D., \& Ansari, D. (2009). Mapping numerical magnitudes onto symbols: the numerical distance effect and individual differences in children's mathematics achievement. Journal of Experimental Child Psychology, 103, 17-29.

Kaufmann, L., Mazzocco, M.M., Dowker, A., von Aster, M., Göbel, S.M. et al. (2013). Dyscalculia from a developmental and differential perspective. Frontiers in Psychology, 4, 516.

Kolkman, M.E., Kroesbergen, E.H., \& Leseman, P.P.M. (2013). Early numerical development and the role of nonsymbolic and symbolic skills. Learning and Instruction, 25, 95-103.

Libertus, M.E., Feigenson, L., \& Halberda, J. (2011). Preschool acuity of the approximate number system correlates with school math ability. Developmental Science, 14, 1292-1300.

Libertus, M.E., Feigenson, L., Halberda, J., \& Landau, B. (2014). Understanding the mapping between numerical approximation and number words: evidence from Williams syndrome and typical development. Developmental Science, 17, 905-919.

McDonald-McGinn, D.M., Sullivan, K.E., Marino, B., Philip, N., \& Swillen, A. et al. (2015). 22q11.2 deletion syndrome. Nature Reviews Disease Primers, 1, 15071.

Mazzocco, M.M.M. (2009). Mathematical learning disability in girls with turner syndrome: a challenge to defining MLD and its subtypes. Developmental Disabilities Research Reviews, 15, $35-44$. 
Mazzocco, M.M.M., Feigenson, L., \& Halberda, J. (2011). Impaired acuity of the approximate number system underlies mathematical learning disability (dyscalculia). Child Development, 82, 1224-1237.

Mazzocco, M.M.M., \& Hanich, L.B. (2010). Math achievement, numerical processing, and executive functions in girls with Turner syndrome: Do girls with Turner syndrome have math learning disability? Learning and Individual Differences, 20, 70-81.

Menon, V. (2015). Arithmetic in the child and adult brain. In R. Cohen Kadosh \& A. Dowker (Eds.), The Oxford handbook of numerical cognition (pp. 502-530). Oxford: Oxford University Press.

Miyake, A., Friedman, N.P., Emerson, M.J., Witzki, A.H., Howerter, A. et al. (2000). The unity and diversity of executive functions and their contributions to complex 'frontal lobe' tasks: a latent variable analysis. Cognitive Psychology, 41, 49-100.

Molko, N., Cachia, A., Rivière, D., Mangin, J.F., Bruandet, M. et al. (2003). Functional and structural alterations of the intraparietal sulcus in a developmental dyscalculia of genetic origin. Neuron, 40, 847-858.

Molko, N., Cachia, A., Rivière, D., Mangin, J.F., Bruandet, M. et al. (2004). Brain anatomy in Turner syndrome: evidence for impaired social and spatial-numerical networks. Cerebral Cortex, 14, 840-850.

Mundy, E., \& Gilmore, C.K. (2009). Children's mapping between symbolic and nonsymbolic representations of number. Journal of Experimental Child Psychology, 103, 490-502.

Murphy, M.M., Mazzocco, M.M.M., Gerner, G., \& Henry, A.E. (2006). Mathematics learning disability in girls with Turner syndrome or fragile X syndrome. Brain and Cognition, 61, 195-210.

Noël, M.P., \& Rousselle, L. (2011). Developmental changes in the profiles of dyscalculia: an explanation based on a double exact-and-approximate number representation model. Frontiers in Human Neuroscience, 5, 165.

OECD (1999). Classifying educational programmes: Manual for ISCED-97 implementation in OECD countries. Paris: OECD

Passolunghi, M.C., \& Lanfranchi, S. (2012). Domain-specific and domain-general precursors of mathematical achievement: a longitudinal study from kindergarten to first grade. British Journal of Educational Psychology, 82, 42-63.

Paterson, S.J., Girelli, L., Butterworth, B., \& KarmiloffSmith, A. (2006). Are numerical impairments syndrome specific? Evidence from Williams syndrome and Down's syndrome. Journal of Child Psychology and Psychiatry, 47, 190-204.

Pickering, S., \& Gathercole, S. (2001). Working Memory Test Battery for Children (WMTB-C). London: Psychological Corporation.

Rasmussen, C., \& Bisanz, J. (2005). Representation and working memory in early arithmetic. Journal of Experimental Child Psychology, 91, 137-157.

Raven, J.C., Court, J.H., \& Raven, J. (1992). Standard progressive matrices. Oxford: Oxford Psychologists Press.
Ross, J.L., Stefanatos, G.A., Kushner, H., Zinn, A., Bondy, C. et al. (2002). Persistent cognitive deficits in adult women with Turner syndrome. Neurology, 58, 218-225.

Rovet, J. (1993). The psychoeducational characteristics of children with Turner syndrome. Journal of Learning Disabilities, 26, 333-341.

Rovet, J. (2004). Turner syndrome: a review of genetic and hormonal influences on neuropsychological functioning. Child Neuropsychology, 10, 262-279.

Rubinsten, O., \& Henik, A. (2009). Developmental dyscalculia: heterogeneity might not mean different mechanisms. Trends in Cognitive Sciences, 13, 92-99.

Schneider, M., Beeres, K., Coban, L., Merz, S., Schmidt, S.S. et al. (2016). Associations of non-symbolic and symbolic numerical magnitude processing with mathematical competence: a meta-analysis. Developmental Science, doi:10.1111/ desc. 12372

Sekuler, R., \& Mierkiewicz, D. (1977). Children's judgments of numerical inequality. Child Development, 48, 630-633.

Sella, F., Lanfranchi, S., \& Zorzi, M. (2013). Enumeration skills in Down syndrome. Research in Developmental Disabilities, 34, 3798-3806.

Simon, T.J. (2011). Clues to the foundation of numerical cognitive impairments: evidence from genetic disorders. Developmental Neuropsychology, 36, 788-805.

Simon, T.J., Bearden, C.E., McDonald-McGinn, D., \& Zackai, E. (2005a). Visuospatial and numerical cognitive deficits in children with chromosome 22q11.2 deletion syndrome. Cortex, 41, 145-155.

Simon, T.J., Bish, J.P., Bearden, C.E., Ding, L., Ferrante, S. et al. (2005b). A multilevel analysis of cognitive dysfunction and psychopathology associated with chromosome 22q11.2 deletion syndrome in children. Development and Psychopathology, 17, 753-784.

Simon, T.J., Takarae, Y., De Boer, T., McDonald-McGinn, D.M., Zackai, E.H. et al. (2008). Overlapping numerical cognition impairments in children with chromosome 22q11.2 deletion or Turner syndromes. Neuropsychologica, 46, 82-94.

Sobin, C., Kiley-Brabeck, K., Daniel, S., Khuri, J., Taylor, L. et al. (2005). Neuropsychological characteristics of children with the 22q11 deletion syndrome: a descriptive analysis. Child Neuropsychology, 11, 39-53.

St Clair-Thompson, H.L., \& Gathercole, S.E. (2006). Executive functions and achievements in school: shifting, updating, inhibition, and working memory. Quarterly Journal of Experimental Psychology, 59, 745-759.

Szücs, D., Devine, A., Soltesz, F., Nobes, A., \& Gabriel, F. (2013). Developmental dyscalculia is related to visuo-spatial memory and inhibition impairment. Cortex, 49, 2674-2688.

Vanbinst, K., Ceulemans, E., Ghesquière, P., \& De Smedt, B. (2015). Profiles of children's arithmetic fact development: a model-based clustering approach. Journal of Experimental Child Psychology, 133, 29-46.

Vanbinst, K., Ghesquière, P., \& De Smedt, B. (2012). Numerical magnitude representations and individual differences in children's arithmetic strategy use. Mind, Brain, and Education, 6 (3), 129-136. doi:10.1111/j.1751-228X.2012.01148.x 
Van Herwegen, J., \& Karmiloff-Smith, A. (2015). Genetic developmental disorders and numerical competence across the lifespan. In R. Cohen Kadosh \& A. Dowker (Eds.), The Oxford handbook of numerical cognition (pp. 705-715). Oxford: Oxford University Press.

Wechsler, D. (1992). Wechsler Intelligence Scale for Children 3rd UK Edition (WISC-III UK). London: Psychological Corporation.

Woodin, M., Wang, P.P., Aleman, D., McDonald-McGinn, D., Zackai, E. et al. (2001). Neuropsychological profile of children and adolescents with the 22q11.2 microdeletion. Genetics in Medicine, 3, 34-39.

Xenidou-Dervou, I., De Smedt, B., van der Schoot, M., \& van Lieshout, E.C.D.M. (2013). Individual differences in kindergarten math achievement: the integrative roles of approximation skills and working memory. Learning and Individual Differences, 28, 119-129.

Xenidou-Dervou, I., van der Schoot, M., \& van Lieshout, E.C.D.M. (2015). Working memory and number line representations in single-digit addition: approximate versus exact, nonsymbolic versus symbolic. Quarterly Journal of Experimental Psychology, 68 (6), 1148-1167. doi:10.1080/ 17470218.2014.977303

Received: 29 May 2015

Accepted: 26 April 2016 